\title{
Influence of Volatile and Nonvolatile Secondary Metabolites From Soybean Pods on Feeding and on Oviposition Behavior of Euschistus heros (Hemiptera: Heteroptera: Pentatomidae)
}

Author(s): Flávia A. C. Silva , Mercedes C. Carrã O-Panizzi , Maria C. BlassioliMoraes , and Antônio R. Panizzi

Source: Environmental Entomology, 42(6):1375-1382. 2013.

Published By: Entomological Society of America

URL: http://www.bioone.org/doi/full/10.1603/EN13081

BioOne (www.bioone.org) is a nonprofit, online aggregation of core research in the biological, ecological, and environmental sciences. BioOne provides a sustainable online platform for over 170 journals and books published by nonprofit societies, associations, museums, institutions, and presses.

Your use of this PDF, the BioOne Web site, and all posted and associated content indicates your acceptance of BioOne's Terms of Use, available at www.bioone.org/page/terms of use.

Usage of BioOne content is strictly limited to personal, educational, and non-commercial use. Commercial inquiries or rights and permissions requests should be directed to the individual publisher as copyright holder. 


\title{
Influence of Volatile and Nonvolatile Secondary Metabolites From Soybean Pods on Feeding and on Oviposition Behavior of Euschistus heros (Hemiptera: Heteroptera: Pentatomidae)
}

\author{
FLÁVIA A. C. SILVA, ${ }^{1}$ MERCEDES C. CARRÃO-PANIZZI, ${ }^{2}$ MARIA C. BLASSIOLI-MORAES, ${ }^{3}$ \\ AND ANTÔNIO R. PANIZZI ${ }^{2,4}$
}

\begin{abstract}
Environ. Entomol. 42(6): 1375-1382 (2013); DOI: http://dx.doi.org/10.1603/EN13081
ABSTRACT Identification of chemical compounds extracted from host plants that act as oviposition stimulants for pest insects has gained importance, because of the compounds' potential use in the manipulation of insect behavior in the field. However, for generalist insects, such as phytophagous pentatomids, the chemical basis for the selection of the host is not well-known. Insect response can vary according to the soybean genotypes. Chemical profile of soybean pods of cultivars 'BRS 213', 'BRS 267 ', 'BR-16', and 'IAC-100' were compared regarding the feeding preference and oviposition of the stink bug Euschistus heros (F.). In the no-choice test, E. heros females showed longer feeding time on pods of BR-16 (132.6 $\mathrm{min}$ ), followed by BRS 213 (128.0 $\mathrm{min}$ ), BRS 267 (122.5 $\mathrm{min}$ ), and IAC-100 (82.9 $\min$ ). In the choice test, there was no significant difference in the feeding time among cultivars. In the oviposition test, females deposited 60\% of eggs on the pods of BRS 267, followed by BRS 213 $(27.3 \%)$, BR-16 (8.8\%), and IAC-100 (3.9\%). The chemical profile of BRS 267 including greater presence of reducing sugars and lack of isoflavone forms might explain the preference of $E$. heros to oviposite on it compared with the remaining cultivars tested.
\end{abstract}

KEY WORDS Glycine max, cultivar, sugar, isoflavone, stink bug

Phytochemical compounds are known to influence the feeding behavior of herbivorous insects; however, there is abundant evidence that these compounds may also affect these insects' oviposition behavior (Bernays and Chapman 1994, Hilker and Meiners 2002). Many studies conducted in this area show that females of specialist insects (mono- and oligophagous) select the host plant based on the presence of phytochemicals that are characteristic of the family of plants preferentially used by the immature insects (Städler 1992). However, for generalist insects (polyphagous), such as most phytophagous pentatomids, the chemical basis for the selection of the host is not well-known.

The neotropical brown stink bug, Euschistus heros (F.), is considered one of the worst pests of soybean, Glycine $\max$ (L.) Merrill (Panizzi et al. 2000), and although polyphagous, it shows a preference for this legume (Panizzi and Oliveira 1998). This preference indicates that soybean exhibits not only nutritional characteristics that are favorable to the development but also phytochemicals that are attractive to this bug.

\footnotetext{
${ }^{1}$ Embrapa Soja, Rod. Carlos João Strass, Acesso Orlando Amaral, Caixa Postal 231, Londrina, PR, Brazil.

${ }_{2}$ Embrapa Trigo, BR 285, Km 294, Caixa Postal 451, Passo Fundo, RS, Brazil.

${ }^{3}$ Embrapa Recursos Genéticos e Biotecnologia, Parque Estação Biológica-PqEB, Avenida W5 Norte, Caixa-Postal 02372, Brasília, DF, Brazil.

${ }^{4}$ Corresponding author, e-mail: antonio.panizzi@embrapa.br.
}

Insect response can vary according to the soybean genotype; therefore, we conducted experiments with E. heros to compare its feeding and oviposition behavior on the soybean cultivars 'BRS 213', 'BRS 267', 'BR-16', and 'IAC-100.' The first three were chosen because they are special types soybean used for human nutrition and have different chemical profiles from the standard conventional cultivars (CarrãoPanizzi et al. 2009); the last cultivar was chosen because it has insect resistance chemical traits (Rossetto et al. 1995). Among the soybean phytochemicals studied, particular attention has been paid to the nonvolatile compounds (sugars and isoflavones), isoflavones, which include the glucoside compounds genistin, daidzin, and glycitin, as well as their corresponding aglycone forms, genistein, daidzein, and glycitein (MacLeod and Ames 1988), and the acetyl and malonyl forms (Kudou et al. 1991). These compounds have been reported to be feeding deterrents for stink bugs (Toledo et al. 2006), and are associated with the resistance mechanisms of some soybean cultivars (Rao et al. 1990, Rossetto et al. 1995).

The importance of volatile compounds was evaluated because previous studies have shown that pentatomids deposit significantly more egg masses in areas treated with the odor plume from volatile extracts compared with nontreated areas (Panizzi et al. 2004). In addition, E. heros females responded to volatiles from soybean plants at the vegetative stage (Michereff 
et al. 2011), and to the volatiles present in the extract of soybean pods (Silva et al. 2007).

Therefore, the aim of this study was to evaluate the chemical profile of different soybean cultivars and the influence of no-volatile chemicals from soybean pods on the feeding and oviposition behavior of E. heros. Pods were chosen to be analyzed, as stink bugs prefer to feed on and colonize soybean plants bearing pods.

\section{Materials and Methods}

Cultivation of Soybean Plants. Soybean seeds of the BRS 213, BRS 267, BR-16, and IAC-100, from the germplasm bank of Embrapa Soybean, Brazil, were sown in plastic pots (5.0 liters) containing sterilized soil provided by Embrapa. The pots were placed in a greenhouse under controlled temperature $\left(27^{\circ} \mathrm{C}\right)$, relative humidity (RH; $70 \pm 10 \%)$, light (25,000 lux), and a photoperiod of 14:10 (L:D) h. In all tests, plants were in the reproductive stage (R6; pod-filling; Fehr et al. 1971). Pods of similar size were hand picked at random, placed in plastic bags, and taken to the laboratory for the chemical analysis.

Extraction, Identification, and Quantification of the Volatile Compounds of Pods From Different Soybean Cultivars. We placed $25 \mathrm{~g}$ of soybean pods of the different cultivars separately in glass chambers (5 liters) adapted for the collection of volatile compounds; three replicates for each cultivar were settled. Two holes were made in the lid of each chamber to connect glass tubing ( $8.0 \mathrm{~cm}$ in length and $0.7 \mathrm{~cm}$ in diameter) that contained $60 \mathrm{mg}$ of the chemical adsorbent Super Q, 80/100 mesh (Alltech Associates Inc., Deerfield, IL). The chambers were aerated for $24 \mathrm{~h}$ using air filtered through activated carbon at a continuous flow rate of $1.200 \mathrm{ml} / \mathrm{min}$. The trapped volatiles were eluted from adsorbent using $1 \mathrm{ml}$ of $n$-hexane and preconcentrated to $200 \mu \mathrm{l}$ under a pure $\mathrm{N}_{2}$ flow. One hundred and fifty microliters of each extract were separated for bioassays, and the other $50 \mu$ l were used in chemical analyses (gas chromatography coupled to flame ionization detector and gas chromatography coupled to mass spectrometry), and both were stored at $-20^{\circ} \mathrm{C}$ until use.

The extracts were analyzed by gas chromatography (Perkin-Elmer, Überlingen, Germany) using a DB-5 column (30 $\mathrm{m}$ in length with a $0.25-\mathrm{mm}$ internal diameter and 0.25- $\mu$ m-thick film; J\&W Scientific, Folsom, CA). The column was maintained at $50^{\circ} \mathrm{C}$ for 2 min, and the temperature was programmed to rise subsequently to $180^{\circ} \mathrm{C}$ at a rate of $5^{\circ} \mathrm{C} / \mathrm{min}$ and hold for $0.1 \mathrm{~s}$ and later to $250^{\circ} \mathrm{C}$ at a rate of $10^{\circ} \mathrm{C} / \mathrm{min}$ and hold for $20 \mathrm{~min}$. The size of the injected sample was $1.0 \mu \mathrm{l}$. Data were collected with the Software Autosystem and analyzed using the Origin 5.0 program (Microcal Software). For the GC analyses, $50 \mu \mathrm{l}$ of each extract was separated, and $1 \mu \mathrm{l}$ of tetracosane was added as internal standard (IS), for a final concentration of 5 $\mu \mathrm{g} / \mathrm{ml}$ of the IS. One microliter of each sample was injected using a splitless mode, with helium as carrier gas. To quantify the compounds, the area of the peak of each compound was compared with the area of the internal standard. For qualitative analysis, selected extracts of each cultivar were analyzed by gas chromatography coupled with mass spectrometry (GCMS) using a mass selective detector (Shimadzu QP2010, Schimadzu Corp., Kyoto, Japan) with electron impact ionization $(70 \mathrm{eV})$. A TRB-5 column was used (30 $\mathrm{m}$ in length with a $0.25-\mathrm{mm}$ internal diameter and 0.25- $\mu$ m-thick film; Teknokroma, Barcelona, Spain) using the same temperature program as in the gas chromatography analysis described above. The injector was held at $250^{\circ} \mathrm{C}$, and the injection was made in splitless mode. The transfer line was maintained at $250^{\circ} \mathrm{C}$. Identifications were made by comparison of spectra with library databases (National Institute of Standards and Technology [NIST] 2008) or with published spectra and using retention index (published at Pherobase and NIST Chemistry Web Book Web sites) and confirmed using authentic standards when available.

Extraction, Identification, and Quantification of the Sugars Present in the Pods From Different Soybean Cultivars. To determine the total reducing sugars present in the different soybean cultivars, Somogyi (1945) and Nelson (1944) analyses were performed. Samples of whole soybean pods (R6) were initially dehydrated in an oven at $30^{\circ} \mathrm{C}$ for $24 \mathrm{~h}$. The dried material was ground in a blender to yield whole-grain flour. Portion of the whole-grain flour ( $1.0 \mathrm{~g}$ each) was placed separately in a 250-ml Erlenmeyer flask with $100 \mathrm{ml}$ of distilled water and $5.0 \mathrm{ml}$ of concentrated sulfuric acid. The solution was subsequently left in a water bath at $65^{\circ} \mathrm{C}$ for $30 \mathrm{~min}$. The solution was cooled to $15^{\circ} \mathrm{C}$, and neutralized using $\mathrm{NaOH}$ to $\mathrm{pH}=7.1$ (5 N). The solution was diluted to a final volume of 200 $\mathrm{ml}$ with distilled water using a volumetric flask and was subsequently filtered through filter paper. A 1-ml sample of the filtered material was placed in a test tube, and $1.0 \mathrm{ml}$ of the Somogyi reaction solution was added. The test tube was capped with marbles, and the mixture was placed in a boiling water bath for $10 \mathrm{~min}$. The tubes were cooled in tap water, and $1.0 \mathrm{ml}$ of the Nelson reaction solution and $7.0 \mathrm{ml}$ of distilled water were added thereafter. The solution was stirred with a magnetic stirrer for $3 \mathrm{~min}$. Three repetitions were performed for each sample, and the samples were analyzed using a diode array UV/Visible spectrophotometer (Cecil model 3000, Cambridge, UK) with the absorbance set at $535 \mathrm{~nm}$.

Extraction, Identification, and Quantification of the Isoflavones Present in the Pods from Different Soybean Cultivars. To identify and quantify the isoflavones present in soybean pods, fresh pods (at the R6 stage) from each cultivar were separately ground, and $100 \mathrm{mg}$ of grounded pods were placed into test tubes containing $4.0 \mathrm{ml}$ of $70 \%$ aqueous ethanol with $0.1 \%$ acetic acid and kept for $1 \mathrm{~h}$ at room temperature and agitated each during 15 min using a vortex; aliquots of $1.5 \mathrm{ml}$ of each sample were centrifuged for $15 \mathrm{~min}$ at $14,000 \mathrm{rpm}$ at $4^{\circ} \mathrm{C}$ (Eppendorf mod. 5417R centrifuge). Then the supernatant was separated, filtered through a $0.45-\mu \mathrm{m}$ membrane and transferred to $2-\mathrm{ml}$ glass flasks. The isoflavones were analyzed by liquid chro- 


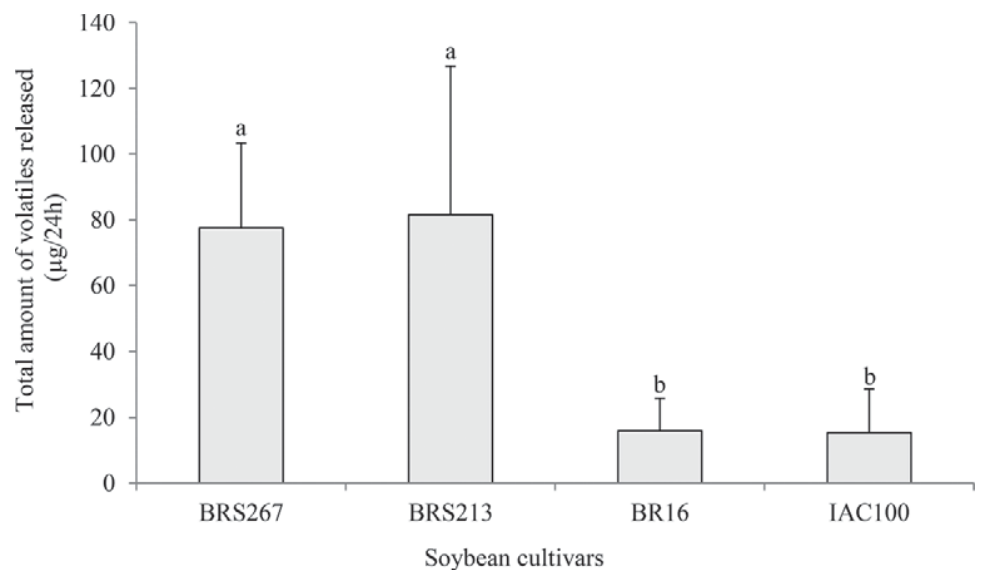

Fig. 1. Total amount of volatiles released (mean $\mu \mathrm{g} / 24 \mathrm{~h} \pm \mathrm{SEM}$ ) by soybean pods from BRS 213, BRS 267, BR-16, and IAC-100 cultivars. The total amount released differed by analysis of deviance (ANODEV); the contrast analysis did not show significant differences between the means of the cultivars.

matography (Waters, mod. 2690, Milford, MA) equipped with a binary pump delivery system and a diode array detector. Three $20-\mu$ l aliquots of each sample were injected onto a 250-mm-long ODS C18 reverse-phase column (YMC Pack ODS-AM Column, with an internal diameter of $0.4 \mathrm{~mm}$ and $5 \mu \mathrm{m}$ of particles) using an automatic sample injector. The mobile phase consisted of: methanol with $0.025 \%$ trifluoroacetic acid (TFA; solvent A) and ultrapure deionized distilled water containing $0.025 \%$ TFA (solvent B). The initial condition was $20 \%$ of solvent A, which reached $100 \%$ at $40 \mathrm{~min}$ and later returned to $20 \%$ at 41 min. This condition was maintained until the 60-min mark. The flow rate of the mobile phase was $1.0 \mathrm{ml} / \mathrm{min}$, and the temperature during the run was $24^{\circ} \mathrm{C}$. For the detection of isoflavones, photodiode array detector was used (Waters, model 996, Milford, MA), adjusted to a wavelength of $260 \mathrm{~nm}$.

To identify the peaks corresponding to each isoflavone, authentic standards were used for glycitin, daidzin, daidzein, and genistein (Sigma-Aldrich), solubilized in methanol (high performance liquid chromatographygrade) at concentrations of $0.00625,0.0125,0.0250$, 0.0500 , and $0.1000 \mathrm{mg} / \mathrm{ml}$, respectively. To quantify the 12 forms of isoflavones by peak area, external standards were used as references, and the molar extinction coefficient of each compound was used to calculate the other forms (malonyl and acetyl).

Feeding Time of $\boldsymbol{E}$. heros on Pods from Different Soybean Cultivars. Females of $E$. heros raised in the laboratory were fasted for $20 \mathrm{~h}$ with water provided ad libitum. To conduct the no-choice test, the fasting females $(N=20)$ were placed individually in petri dishes $(6.0 \mathrm{~cm}$ in diameter) containing a pod (R6) from one of the tested soybean cultivars. In the choice test, the females $(N=20)$ were placed individually in clear plastic boxes ( 11.0 by 11.0 by $3.5 \mathrm{~cm}$ ) containing a pod of each soybean cultivar, randomly arranged. The analyses were conducted in a temperature-controlled room $\left(25 \pm 1^{\circ} \mathrm{C}\right)$, and the insects were observed for $4 \mathrm{~h}$. We evaluated the feeding time (min- utes) for each soybean cultivar. Feeding time was characterized as the interval of time from the start of vertical head movements after the insertion of mouthparts into the pod wall to the withdrawal of the stylets (Depieri and Panizzi 2011).

Oviposition Behavior of $E$. heros on Pods from Different Soybean Cultivars. In the choice test, 15 E. heros breeding pairs that were $10 \mathrm{~d}$ old and raised in the laboratory were individually placed in clear plastic boxes ( 11.0 by 11.0 by $3.5 \mathrm{~cm}$ ) containing a pod (R6) from each tested soybean cultivar. The insects were kept under controlled conditions $\left(25 \pm 1^{\circ} \mathrm{C}, 70 \pm 5 \%\right.$ RH, and a photoperiod of 14:10 [L:D] h) and observed daily for $4 \mathrm{~d}$. The average number and percentage of egg layings were calculated.

Statistical Analyses. The average concentration of sugars and isoflavones, and average feeding time in each soybean cultivar were evaluated using analysis of variance (ANOVA). The average feeding time was compared using the Kruskal Wallis and the Tukey's test for the choice and the no-choice tests, respectively. The egg laying percentages were transformed into arcsine $\mathcal{V}(x+1)$ for comparison with Tukey's test. Analyses were performed using the statistical program SAS (SAS Institute 2009). The amount of volatiles released by each cultivar and the differences in the amounts of each compounds released by the cultivars were accessed using generalized linear model (GLM). Therefore, the total amounts of volatile chemicals (VOCs) released from each treatment overtime were compared using GLM, and deviance analyses (ANODEV) with gamma distribution and inverse as link function. When the analyses showed significant effects of treatments, means were compared using contrast analyses. For GLM, the statistical program used was R Software version 2.15.2 (R Development Core Team 2012).

Chemicals. Super Q (80-100 mesh) was purchased from Alltech (PA). Hexane for HPLC ( $\geq 97 \%$ and redistilled), (Z)-3-hexen-1-ol (98\%), hexanol (98\%), nonanol (98\%), 1-octen-3-ol (8\%), (E)-2-nonen-1-ol (96\%), $\alpha$-pinene (98\%), nonanal (95\%), decanal 
Table 1. The mean concentration \pm SD $(\mu \mathrm{g} / 24 \mathrm{~h} \pm \mathrm{SEM})$ of the volatile compounds extracted by forced aeration from pods of the soybean cultivars BRS 213, BRS 267, BR-16, and IAC-100

\begin{tabular}{|c|c|c|c|c|c|}
\hline \multirow{2}{*}{ Compounds } & \multicolumn{5}{|c|}{ Average concn $( \pm \mathrm{SEM})^{a}$} \\
\hline & Retention index & BRS 213 & BRS 267 & BR-16 & IAC-100 \\
\hline (Z)-3-hexen-1-ol & 898 & $9.034 \pm 2.072 b$ & $2.945 \pm 1.798 \mathrm{a}$ & $4.777 \pm 4.369 \mathrm{a}$ & $0.457 \pm 0.385 \mathrm{a}$ \\
\hline (E)-2-hexenal & 857 & $3.305 \pm 1.320 \mathrm{~b}$ & $2.933 \pm 0.386 b$ & $0.704 \pm 0.333 \mathrm{a}$ & $0.362 \pm 0.425 \mathrm{a}$ \\
\hline Hexanol & 862 & $0.058 \pm 0.017 \mathrm{a}$ & $0.518 \pm 0.303 a$ & $\mathrm{Nd}^{b}$ & $0.383 \pm 0.456 a$ \\
\hline$\alpha$-pinene & 941 & $0.012 \pm 0.015 \mathrm{a}$ & $0.152 \pm 0.085 \mathrm{a}$ & $\mathrm{Nd}$ & $0.516 \pm 0.462 \mathrm{a}$ \\
\hline Camphene & 957 & $\mathrm{Nd}$ & $1.955 \pm 0.468 \mathrm{~b}$ & $0.253 \pm 0.068 a$ & $0.525 \pm 0.489 a$ \\
\hline 1-octen-3-ol & 982 & $51.360 \pm 46.184 b$ & $37.001 \pm 29.752 \mathrm{~b}$ & $4.224 \pm 2.952 \mathrm{a}$ & $0.742 \pm 0.392 \mathrm{a}$ \\
\hline 3-octanone & 988 & $9.560 \pm 2.739 b$ & $7.622 \pm 2.062 b$ & $2.369 \pm 1.355 \mathrm{a}$ & $0.509 \pm 0.548 a$ \\
\hline (Z)-3-hexenyl acetate & 1010 & $1.009 \pm 0.467 \mathrm{a}$ & $4.046 \pm 2.532 b$ & $0.615 \pm 0.173 \mathrm{a}$ & $0.504 \pm 0.599 a$ \\
\hline Undecane & 1100 & $0.114 \pm 0.006 \mathrm{a}$ & $0.700 \pm 0.303 \mathrm{a}$ & $0.074 \pm 0.025 \mathrm{a}$ & $1.098 \pm 0.393 \mathrm{a}$ \\
\hline Nonanal & 1107 & $0.351 \pm 0.053 \mathrm{a}$ & $2.063 \pm 1.070 \mathrm{a}$ & $0.258 \pm 0.174 a$ & $0.660 \pm 0.680 \mathrm{a}$ \\
\hline (E)-2-none-1-ol & 1170 & $0.258 \pm 0.026 \mathrm{a}$ & $0.328 \pm 0.161 \mathrm{a}$ & $0.804 \pm 0.884 a$ & $0.795 \pm 0.702 \mathrm{a}$ \\
\hline Nonanol & 1172 & $0.106 \pm 0.130 \mathrm{a}$ & $0.185 \pm 0.227 \mathrm{a}$ & $0.042 \pm 0.019 \mathrm{a}$ & $0.571 \pm 0.358 \mathrm{a}$ \\
\hline Dodecane & 1200 & $0.063 \pm 0.009 \mathrm{a}$ & $0.292 \pm 0.140 \mathrm{a}$ & $0.027 \pm 0.013 \mathrm{a}$ & $1.121 \pm 0.540 \mathrm{a}$ \\
\hline Decanal & 1207 & $0.373 \pm 0.030 \mathrm{a}$ & $1.873 \pm 1.064 \mathrm{a}$ & $0.196 \pm 0.082 \mathrm{a}$ & $0.686 \pm 0.834 a$ \\
\hline Tridecane & 1300 & $0.267 \pm 0.114 \mathrm{a}$ & $1.453 \pm 0.749 a$ & $0.140 \pm 0.097 \mathrm{a}$ & $0.865 \pm 0.874 a$ \\
\hline Geranyl acetone & 1466 & $0.147 \pm 0.083 a$ & $0.703 \pm 0.319 a$ & $\mathrm{Nd}$ & $1.036 \pm 1.006 \mathrm{a}$ \\
\hline Pentadecane & 1500 & $0.390 \pm 0.242 \mathrm{a}$ & $3.392 \pm 0,483 \mathrm{a}$ & $0.381 \pm 0.246 \mathrm{a}$ & $1.069 \pm 1.040 \mathrm{a}$ \\
\hline Hexadecane & 1600 & $0.461 \pm 0.149 \mathrm{a}$ & $2.302 \pm 1.137 \mathrm{a}$ & $0.172 \pm 0.109 a$ & $1.264 \pm 1.062 \mathrm{a}$ \\
\hline
\end{tabular}

${ }^{a}$ Mean values followed by the same letters in rows are not significantly different according to contrast analyses $(P<0.05)$.

${ }^{b} \mathrm{Nd}$, nondetected.

(98\%), 3-octanone (98\%), $\alpha$-camphene (90\%), (Z)-3hexenyl acetate (98\%), undecane (99\%), dodecane $(0 \%)$, tridecane $(99 \%)$, pentadecane $(98 \%)$, hexadecane $(99 \%)$, glycitin $(\geq 97 \%)$, daidzin ( $\geq 95 \%)$, daidzein $(\geq 98 \%)$, and genistein ( $\geq 98 \%)$ isoflavones were purchased from Sigma-Aldrich (Steinheim, Germany). (E)-2-hexenal was purchased from TCI-America (Portland, USA). Geranylacetone (mixture of isomers; 96\%) was purchased from TCI (Tokyo, Japan).

\section{Results}

Identification and Quantification of Volatile Compounds from Pods of Different Soybean Cultivars. The analysis of the chemical profiles of pods from the different soybean cultivars showed similar volatile compositions but with different amounts. The total amount of VOCs produced by pods differed among the cultivars (ANODEV, $\chi^{2}=12.1$; $\mathrm{df}=3 ; P=0.007$; Fig. 1). The production of the following compounds
(E)-2-hexenal (ANODEV, $\chi^{2}=10.1 ; \mathrm{df}=3 ; P<0.02$ ), 1-octen-3-ol (ANODEV, $\chi^{2}=21.8$; df $=3 ; P<0.001$ ) and 3-octanone (ANODEV, $\chi^{2}=14.4$; df $=3 ; P=$ 0.002), (Z)-3-hexen-1-ol (ANODEV, $\chi^{2}=22.8$; df = 3; $P<0.001$ ), camphene (ANODEV, $\chi^{2}=9.99$; $\mathrm{df}=3$; $P=0.02$ ), and (Z)-3-hexenyl acetate (ANODEV, $\chi^{2}=$ 8.5; df $=3 ; P=0.04)$ differed among the cultivars evaluated (Table 1), and several compounds were not detected at all, such as hexanol, geranyl acetone, and $\alpha$-pinene in BR-16, and camphene in BRS 213 (Table $1)$. The contrast analysis comparing the different cultivars did not show significant difference.

Quantification of Reducing Sugars from Pods of Different Soybean Cultivars. There was significant difference $(F=19.892 ; \mathrm{df}=3 ; P=0.0001)$ in the concentration of reducing sugars present in the whole pods from the different soybean cultivars. The Somogyi and Nelson analyses showed that the average and the standard error of reducing sugars in the whole pods were $98.6 \pm 4.5$,

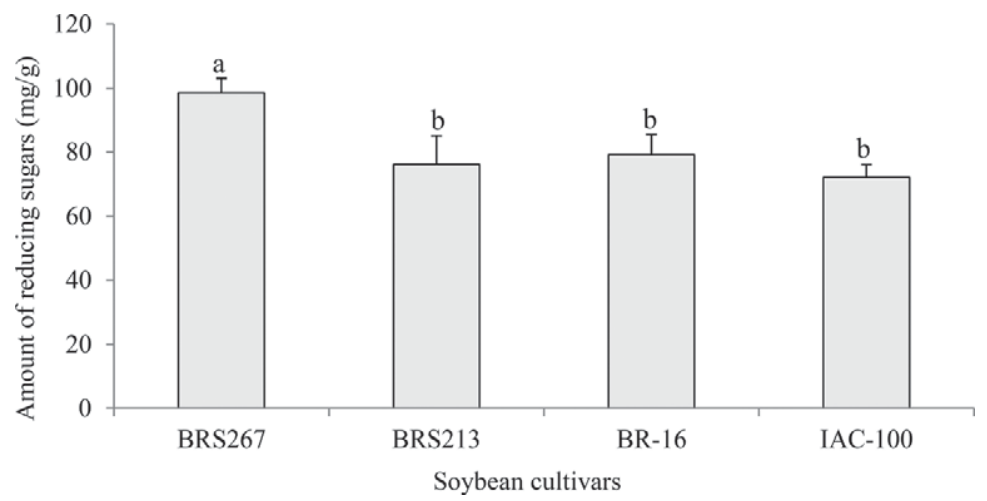

Fig. 2. Mean amount $(\mathrm{mg} / \mathrm{g} \pm \mathrm{SEM})$ of reducing sugars present in soybean pods from BRS 213, BRS 267, BR-16, and IAC-100 cultivars. Mean values followed by the same letter are not significantly different according to the Tukey's test $(P<0.05)$. 


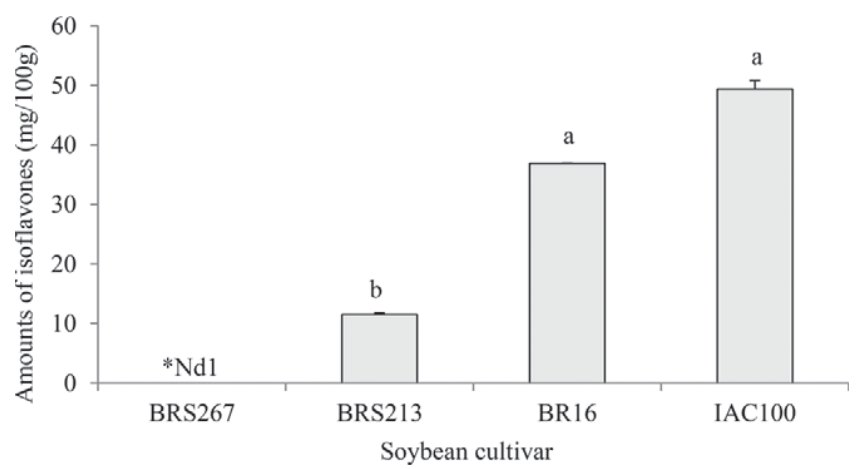

Fig. 3. Mean amount $(\mathrm{mg} / 100 \mathrm{~g} \pm \mathrm{SEM})$ of isoflavones present in soybean pods from BRS 213, BR-16, and IAC-100 cultivars. Mean values followed by the same letter are not significantly different according to the Tukey's test $(P<0.05)$. *Nd, nondetected.

$79.2 \pm 6.2,76.1 \pm 9.1$, and $72.1 \pm 3.9 \mathrm{mg} / \mathrm{g}$ for BRS 267 BR-16, BRS 213, and IAC-100, respectively (Fig. 2).

Quantification of Isoflavones from Pods of Different Soybean Cultivars. The concentration of isoflavones varied among the analyzed cultivars. IAC-100 and BR-16 showed the highest total isoflavone levels of $49.4 \pm 1.416$ and $37.0 \pm 0.079 \mathrm{mg} / 100 \mathrm{~g}$, respectively, while BRS 213 had the lowest concentration (11.5 \pm $0.284 \mathrm{mg} / 100 \mathrm{~g} ; F=7.24 ; \mathrm{df}=3 ; P=0.025)$. None of the 12 isoflavone forms was detected in the BRS 267 samples (Fig. 3). In general, there were low levels of isoflavones in each cultivar. The isoflavones daidzin and glycitin were detected only in IAC-100 at concentrations of $4.13 \pm 0.10$ and $1.13 \pm 0.03 \mathrm{mg} / 100 \mathrm{~g}$, respectively (Table 2 ).

Feeding Time of $\boldsymbol{E}$. heros on Pods of Different Soybean Cultivars. In the choice test, there was no significant difference $(F=2.03$; $\mathrm{df}=3 ; P=0.117)$ in the feeding time among cultivars (Fig. 4). However, in the no-choice test, $E$. heros females showed feeding preference for pods of BRS 213 and BR-16 ( $F=6.17$; $\mathrm{df}=3 ; P=0.0009)$, with a feeding time of $128.0 \pm 18.8$

Table 2. The mean concentration $(\mathrm{mg} / 100 \mathrm{~g} \pm \mathrm{SEM})$ of isoflavones present in soybean pods of the cultivars BRS 213 , BR-16, and IAC-100

\begin{tabular}{lccc}
\hline \hline \multirow{2}{*}{ Isoflavonas $^{a}$} & \multicolumn{3}{c}{ Mean concn $( \pm \mathrm{SEM})^{b}$} \\
\cline { 2 - 4 } & BRS 213 & BR-16 & \multicolumn{1}{c}{ IAC-100 } \\
\hline Daidzin & $0.00 \pm 0.00 \mathrm{Bd}$ & $0.00 \pm 0.00 \mathrm{Bd}$ & $4.13 \pm 0.10 \mathrm{Ad}$ \\
Glycitin & $0.00 \pm 0.00 \mathrm{Bd}$ & $0.00 \pm 0.00 \mathrm{Bd}$ & $1.13 \pm 0.03 \mathrm{Ae}$ \\
Genistin & $1.54 \pm 0.04 \mathrm{Bc}$ & $4.47 \pm 0.03 \mathrm{Ac}$ & $5.98 \pm 0.23 \mathrm{Ac}$ \\
Malonyl Daidzin & $0.00 \pm 0.00 \mathrm{Ad}$ & $0.00 \pm 0.00 \mathrm{Ad}$ & $0.00 \pm 0.00 \mathrm{Af}$ \\
Malonyl Glycitin & $2.57 \pm 0.42 \mathrm{Bb}$ & $4.07 \pm 0.03 \mathrm{Ac}$ & $5.12 \pm 0.19 \mathrm{Ac}$ \\
Malonyl Genistin & $0.00 \pm 0.00 \mathrm{Cd}$ & $3.82 \pm 0.12 \mathrm{Bc}$ & $8.96 \pm 0.33 \mathrm{Ab}$ \\
Acetyl Daidzin & $0.00 \pm 0.00 \mathrm{Ad}$ & $0.00 \pm 0.00 \mathrm{Ad}$ & $0.00 \pm 0.00 \mathrm{Af}$ \\
Acetyl Glycitin & $0.00 \pm 0.00 \mathrm{Ad}$ & $0.00 \pm 0.00 \mathrm{Ad}$ & $0.00 \pm 0.00 \mathrm{Af}$ \\
Acetyl Genistin & $0.00 \pm 0.00 \mathrm{Ad}$ & $0.00 \pm 0.00 \mathrm{Ad}$ & $0.00 \pm 0.00 \mathrm{Af}$ \\
Daidzein & $3.71 \pm 0.18 \mathrm{Ba}$ & $8.28 \pm 0.04 \mathrm{Ab}$ & $8.63 \pm 0.20 \mathrm{Ab}$ \\
Glycitein & $0.00 \pm 0.00 \mathrm{Ad}$ & $0.00 \pm 0.00 \mathrm{Ad}$ & $0.00 \pm 0.00 \mathrm{Af}$ \\
Genistein & $3.66 \pm 0.10 \mathrm{Ba}$ & $16.28 \pm 0.06 \mathrm{Aa}$ & $15.45 \pm 0.39 \mathrm{Aa}$ \\
\hline
\end{tabular}

\footnotetext{
${ }^{a}$ No isoflavones were detected in the BRS 267 cultivar.

${ }^{b}$ Mean values followed by the same uppercase letters in rows and lower case letters in columns are not significantly different according to contrast analyses $(P<0.05)$.
}

and $132.7 \pm 16.8 \mathrm{~min}$, respectively, followed by BRS 267, with a feeding time of $122.5 \pm 19.2$ min (Fig. 4).

E. heros Oviposition Behavior on Pods of Different Soybean Cultivars. The E. heros oviposition behavior on the different soybean cultivars varied. As shown in Fig. 5, females deposited $60 \%$ of their egg masses on pods of BRS 267, showing significant $(F=19.487$; df $=$ 3; $P=0.0001)$ preference for this cultivar followed by BRS 213 (27.3\%), BR-16 (8.8\%), and IAC-100 (3.9\%).

\section{Discussion}

The bioassays results suggest that $E$. heros females preferred to laid eggs on BRS 267, compared with the other cultivars. Although there is no data published on the possible susceptibility of the BRS 267 to stink bugs compared with conventional cultivars, preliminary assumptions related to the chemical profile of BRS 267 (e.g., higher sugar content; Carrão-Panizzi et al. 2006, Silva et al. 2009) suggest stink bug preference. BRS 267 presented the same volatile composition as did the other studied cultivars, but the total amount of volatiles released was different. In addition, compounds 1-octen-3-ol, 3-octanone, and (E)-2-hexenal were identified in higher amounts in BRS 267 and BRS 213, which are compounds known to have influence on insects (Pires et al. 2001).

The chemical profile of volatiles obtained from soybean pods is different from the chemical profile of volatiles obtained from vegetative (V3) soybean plants (Moraes et al. 2008, Michereff et al. 2011). The IAC-100 and Dowling cultivars at the vegetative stage presented several volatiles compounds such as methyl salicylate, benzothiazole, indole, $(E, E)$ - $\alpha$-farnesene, $\beta$-caryophyllene, and $\alpha$-caryophyllene, which were not detected from soybean pods in this work. Whereas the green leaf volatiles identified from IAC-100 and Dowling at the vegetative stage- $(Z)-3$-hexenyl acetate, $(E)$-2-hexenal, and $(Z)$-3-hexen-1-ol-also were identified in this work. Soybean plants have the chemical profile of volatiles altered with the stage, that is, older plants and reproductive structures release less 


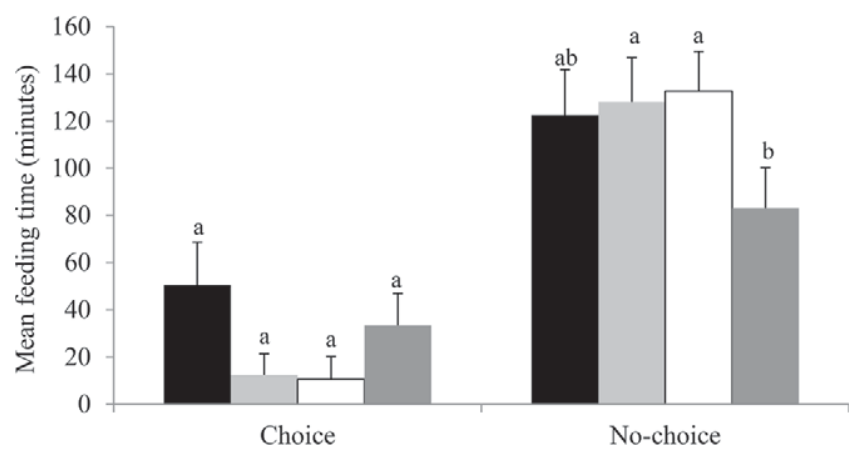

Fig. 4. Mean feeding time ( $\min \pm \mathrm{SEM}$ ) of $E$. heros females on pods of different soybean cultivars. Mean values followed by the same letter among treatments are not significantly different according to the Kruskall-Wallis test $(P<0.05)$, in the choice-test, and to the Tukey's test $(P<0.05)$, in the no-choice test.

volatiles compared with young leaf and plants (Róstas and Eggert 2008).

Results suggest that nonvolatile compounds might be involved in the choice of $E$. heros females to laid eggs and feed on the soybean pods. The results showed that $E$. heros females preferred to laid eggs on BRS 267, which presented the lowest level of flavonoids and higher level of sugar. Carrão-Panizzi et al. (2006) found that seeds of this cultivar have higher concentration of sucrose, which gives it a sweet taste. This feature can have a phagostimulant effect on insects (Tester 1977). Hou et al. (2008) studying different varieties of soybean reported a range in the total sugar concentration from 37.2 to $148.7 \mathrm{mg} / \mathrm{g}$; the cultivars analyzed in this work presented a total amount of sugar concentration from 70 to $100 \mathrm{mg} / \mathrm{g}$. Sugars play an important role on the behavior of insects, acting as phagostimulants (Bernays and Chapman 1994) and oviposition stimulants (Eisemann and Rice 1985, Derridj et al.1996), which might explain why bugs preferred to oviposite on BRS 267. In addition, the low level (undetectable) of flavonoids in BRS 267 also might be involved in the preference of $E$. heros females. Several studies show that isoflavones play a critical role in plant resistance against insects (Suther- land et al. 1980, Rao et al. 1990, Piubelli et al. 2005). Preliminary studies indicate that isoflavones exert a negative influence on the oviposition behavior of $E$. heros, reinforcing the importance of these compounds as mediators of stink bug behavior (Silva 2009). The cultivars IAC-100 and BR-16 showed the highest total isoflavone levels. When comparing the isoflavone contents in plants grown in different geographic regions, Carrão-Panizzi et al. (1998) found that the isoflavone concentration ranged from 116.4 to $177.3 \mathrm{mg} / 100 \mathrm{~g}$ in IAC-100 and from 107.1 to $126.5 \mathrm{mg} / 100 \mathrm{~g}$ in BR-16. Carrão-Panizzi and Kitamura (1995) also detected the presence of daidzin in mature grains of IAC-100 in high concentration. Similar high concentrations of daidzein and of genistein were observed in BR-16 and IAC-100 (8.2 and $8.6 \mathrm{mg} / 100 \mathrm{~g}$, and 16.2 and 15.4 $\mathrm{mg} / 100 \mathrm{~g}$, respectively). In BRS 213, the observed daidzein concentration was $3.7 \mathrm{mg} / 100 \mathrm{~g}$, which is significantly greater than that observed by Ribeiro et al. (2007). However, this cultivar showed significantly lower levels of total isoflavones compared with BR-16 and IAC-100.

In studies on the resistance of soybean cultivars to insects, few authors have related the resistance mechanisms to the seeds' chemical composition (Tester

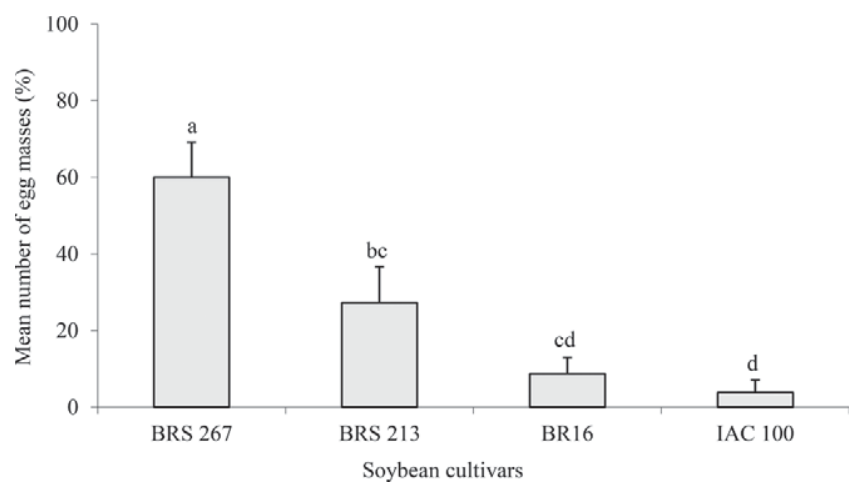

Fig. 5. Mean percentage ( \pm SEM) of E. heros egg layings on pods of different soybean cultivars. Mean values followed by the same letter are not significantly different according to Tukey's test $(P<0.05)$. 
1977, Grunwald and Kogan 1981, Liu et al. 1989); most studies only consider the morphologic, genetic, or both, characteristics of the plant (Jones and Sullivan 1978, Gilman et al. 1982, Ihsan-Ul-Had et al. 2003).

The studied soybean cultivars (BRS 267, BRS 213, BR-16, and IAC-100) were developed through breeding techniques; the fact that they exhibit compounds that are attractive or repellent to insects was not an intended outcome. Given that the chemical factors determining insect resistance in these soybean cultivars have not been elucidated, the results of the volatile, sugar, and isoflavone chemical profiles obtained in the current study can be used as a basis for further research on soybean resistance to insects.

Bugs oviposited more on BRS 267, which has chemical properties that are more attractive: higher volatile and sugar concentrations, and lower isoflavone content. In addition, the physical characteristics of the pods may have influenced the stink bug response; BRS 267 has larger pods and has a lower density of trichomes, while IAC-100 is less attractive, because of its smaller pods and higher density of trichomes, which can prevent the attachment of stink bug eggs. IhsanUl-Had et al. (2003) demonstrated that morphological characteristics, such as leaf area and trichome density, influence the behavior of pest species, determining the soybeans' level of resistance or susceptibility to them.

In conclusion, these results indicate that pods of BRS 267 were preferred as oviposition sites by E. heros females. Preliminary studies (Silva et al. 2007) demonstrated that chemical extracts obtained from pods of this cultivar have a conditioning effect on the oviposition behavior of $E$. heros. This finding supports the possibility of using this cultivar to manipulate the oviposition behavior of stink bugs in the laboratory, facilitating the maintenance of colonies; furthermore, this cultivar could be used in the field as a trap plant.

\section{Acknowledgments}

We thank Miguel Borges and Raul Laumann for the assistance on volatile collections from soybean pods, and Jovenil J. da Silva for support in cultivating the soybean plants. FAC Silva was supported by a scholarship from the Brazilian Council of Science and Technology (CNPq).

\section{References Cited}

Bernays, E. A., and R. F. Chapman. 1994. Host-plant selection by phytophagous insects. Chapman \& Hall, London, United Kingdom.

Carrão-Panizzi, M. C., and K. Kitamura. 1995. Isoflavone content in Brazilian soybean cultivars. Breed. Sci. 45: 295-300.

Carrão-Panizzi, M. C., K. Kitamura, A.D.P. Beléia, and M.C.N. Oliveira. 1998. Influence of growth locations on isoflavone contents in Brazilian soybean cultivars. Breed. Sci. 48: 409-413.

Carrão-Panizzi, M. C., A. E. Pípolo, L. A. Almeida, J.M.G. Mandarino, M. Kaster, C.A.A. Arias, G.E.S. Carneiro, J.F.F. Toledo, L. C., Miranda, J. T. Yorinori, et al. 2006. BRS 267: soybean cultivar for human consumption. Re- search Meeting of Soybean in Central Brazil, 28, Uberaba, Brazil.

Carrão-Panizzi, M. C., A. E. Pípolo, J.M.G. Mandarino, N. E. Arantes, A. Garcia, V. T. Benassi, C.A.A. Arias, M. Kaster, M. F. de Oliveira, M. A. Oliveira, et al. 2009. Breeding specialty soybean cultivars for processing and valueadded utilization at Embrapa in Brazil. In Proceedings of the VIII World soybean Research Conference, Chinese Academy of Agricultural Sciences, Institute of Crop Science, Beijing, China.

Depieri, R. A., and A. R. Panizzi. 2011. Duration of feeding, and superficial and in-depth damage to soybean seed by selected species of stink bugs (Heteroptera: Pentatomidae). Neotrop. Entomol. 40: 197-203.

Derridj, S., B. R. Wu, L. Stammitti, J. P. Garrec, and A. Derrien. 1996. Chemicals on the leaf surface, information about the plant available to insects. Entomol. Exp. Appl. 80: 197-201.

Eisemann, C. H., and M. J. Rice. 1985. Oviposition behavior of Daucus tryoni: effects of some sugars and salts. Entomol. Exp. Appl. 39: 61-71.

Fehr, W. R., C. E. Caviness, D. T. Burmood, and J. S. Pennington. 1971. Stage of development descriptions for soybeans, Glycine max (L.) Merrill. Crop Sci. 11: 929-931.

Gilman, D. F., R. M. McPherson, R. D. Newsom, D. C. Herzog, and C. Williams. 1982. Resistance in soybeans to the southern green stink bug. Crop Sci. 22: 573-576.

Grunwald, C., and M. Kogan. 1981. Sterols of soybeans differing in insect resistance and maturity group. Phytochemistry 20: 765-768.

Hilker, M., and T. Meiners. 2002. Chemoecology of insect eggs and egg deposition. Blackwell Publishers, Berlin, Germany.

Hou, A., P. Chen, A. Shi, B. Zhang, and Y. J. Wang. 2008. Sugar variation in soybean seed assessed with a rapid extraction and quantification method. Int. J. Agron. 2009: $1-8$.

Ihsan-Ul-Had, M. A., S. A. Kakakhel, and M. A. Khokhar. 2003. Morphological and physiological parameters of soybean resistance to insect pests. Asian J. Plant Sci. 2: 202-204.

Jones, W. A., and M. J. Sullivan. 1978. Susceptibility of certain soybean cultivars to damage by stink bugs. J. Econ. Entomol. 71: 534-536.

Kudou, S., Y. Fleury, D. Welti, D. Magnolato, T. Uchida, K. Kitamura, and K. Okubo. 1991. Malonyl isoflavone glycosides in soybean seeds (Glycine $\max$ (L.) Merrill). Agric. Biol. Chem. 55: 2227-2233.

Liu, S. H., D. M. Norris, and P. Lyne. 1989. Volatiles from the foliage of soybean, Glycine max, and lima bean, Phaseolus lunatus: their behavioral effects on the insects Trichoplusia ni and Epilachna varivestis. J. Agric. Food Chem. 37: 496-501.

MacLeod, G., and J. Ames. 1988. Soy flavor and its improvement. CRC Critical Rev. Food Sci. Nutr. 27: 219-243.

Michereff, M.F.F., R. A. Laumann, M. Borges, M. MichereffFilho, I. R. Diniz, A. L. Farias Neto, and M.C.B. Moraes. 2011. Volatiles mediating a plant-herbivore-natural enemy interaction in resistant and susceptible soybean cultivars. J. Chem. Ecol. 37: 273-285.

Moraes, M.C.B., M. Pareja, R. A. Laumann, C. B. HoffmannCampo, M. Borges. 2008. Response of the parasitoid to induced volatiles from soybean damaged by stink bug herbivory and oviposition. J. Plant Interact. 3: 111-118.

Nelson, N. A. 1944. Photometric adaptation of the Somogyi method for the determination of glucose. J. Biol. Chem. 153: 375-380. 
Panizzi, A. R., and E.D.M. Oliveira. 1998. Performance and seasonal abundance of the Neotropical brown stink bug, Euschistus heros nymphs and adults on a novel food plant (pigeonpea) and soybean. Entomol. Exp. Appl. 88: 169 175.

Panizzi, A. R., J. E. McPherson, D. G. James, M. Javahery, and R. M. McPherson. 2000. Stink bugs (Pentatomidae), pp. 474, In C. W. Schaefer and A. R. Panizzi (eds.), Heteroptera of Economic Importance. CRC, Boca Raton, FL.

Panizzi, A. R., M. Berhow, and R. J. Bartelt. 2004. Artificial substrate bioassay for testing oviposition of southern green stink bug conditioned by soybean plant chemical extracts. Environ. Entomol. 33: 1217-1222.

Piubelli, G. C., C. B. Hoffmann-Campo, F. Moscardi, S. H. Miakubo, and M.C.N. Oliveira. 2005. Are chemical compounds important for soybean resistance to Anticarsia gemmatalis? J. Chem. Ecol. 31: 1509-1525.

Pires, C., E. Suji, M. Borges, F. Schmidt, P.H.G. Zarbin, V.C.R. Azevedo, A. L. Lacerda, and D. Pantaleão. 2001 Ação cairomonal de componentes do feromônio de alarme do percevejo da soja, Piezodorus guildinii, sobre o parasitóide de ovos Telenomus podisi, pp. 1-23. Boletim de Pesquisa e Desenvolvimento No 19. Ed. EmbrapaBrasília-DF, Brazil.

Rao, K. V., S. K. Chattopadhyay, and G. C. Reddy. 1990. Flavonoids with mosquito larval toxicity. J. Agric. Food Chem. 38: 1427-1430.

Ribeiro, M.L.L., J.M.G. Mandarino, M. C. Carrão-Panizzi, M.C.N. Oliveira, C. B. Campo, A. L. Nepomuceno, and E. I. Ida. 2007. Isoflavone content and $\beta$-glycosidase activity in soybean cultivars of different maturity groups. J Food Compost. Anal. 20: 19-24.

Rossetto, C. J., P. B. Gallo, L. F. Razera, N. Bertoletto, T. Igue, P. F. Medina, O. Tisselli Filho, V. Aguilera, R.F.A. Veiga, and J. B. Pinheiro. 1995. Mechanisms of resistance to stink bug complex in the soybean cultivar 'IAC-100'. Anais da Sociedade Entomológica do Brasil 24: 517-522.

Róstas, M., and K. Eggert. 2008. Ontogenetic and spatiotemporal patterns of induced volatiles in Glycine max in the light of the optimal defense hypothesis. Chemoecol 18: $28-39$
R Development Core Team. 2012. A language and environment for statistical computing. R Foundation for Statistical Computing, Vienna, Austria.

SAS Institute. 2009. SAS/STAT: user's guide, version 9.2. SAS Institute, Cary, NC.

Silva, F.A.C. 2009. Physical and chemical factors mediating oviposition of phytophagous pentatomids on artificial substrates. Ph.D thesis, Federal University of Paraná, Curitiba, PR, Brazil.

Silva, F.A.C., A. R. Panizzi, R. A. Laumann, M.C.B. Moraes, and M. Borges. 2007. Oviposition of Euschistus heros (L.) (Heteroptera: Pentatomidae) in artificial substrates treated with soybean chemical extract, pp. 115. In Abstracts of the V Brazilian Meeting on Chemical Ecology. Londrina, PR, Brazil.

Silva, J. B., M. C. Carrão-Panizzi, and S. H. Prudêncio. 2009. Chemical and physical composition of grain-type and food-type soybean for food processing. Pesquisa Agropecuária Brasileira 44: 777-784.

Somogyi, M. 1945. Determination of blood sugar. J. Biol. Chem. 160: 69-73.

Städler, E. 1992. Behavioral responses of insect to plant secondary compounds, pp. 256. In G. A. Rosenthal and M. R. Berenbaum (eds.), Herbivores: Their Interactions With Secondary Plant Metabolites, vol. II. Academic, San Diego, CA.

Sutherland, O.R.W., G. B. Russell, D. R. Biggs, and G. A. Lane. 1980. Insect feeding deterrent activity of phytoalexin isoflavonoids. Biochem. Syst. Ecol. 8: 73-75.

Tester, C. 1977. Constituents of soybean cultivars differing in insect resistance. Phytochemistry 16: 18991901.

Toledo, A. M., C. B. Hoffmamnn-Campo, A. L. Boiça-Júnior, M. C. Salvador, S. H. Myakubo, S. H. Silva, and A.C.F. Mendes. 2006. Effect of isoflavonoids on the feeding behavior of the Nezara viridula (L.), pp. 83. In Abstracts of the IV Brazilian Soybean Congress, Londrina, PR.

Received 26 March 2013; accepted 20 August 2013. 